\title{
A EAD E A PÓS-GRADUAÇÃO STRICTO SENSU A DISTÂNCIA NO BRASIL: UMA ABORDAGEM TEÓRICA
}

Rafael Henrique Santin*

Gisele Angelina Bassani**

RESUMO: A EaD se constitui, no Brasil, como uma modalidade de educação regulada pela Lei de Diretrizes e Bases da Educação e presente, predominantemente, no ensino superior. O objeto deste artigo é entender o uso que pode ser feito da EaD no processo de formação de mestres. Assim, pretendemos abordar neste artigo a EaD na pós-graduação stricto sensu no Brasil, enfatizando a estrutura e o funcionamento de um curso de mestrado para a formação de professores da área de matemática que se utiliza da EaD, o Mestrado Profissional em Matemática em Rede Nacional (PROFMAT). Nossa pesquisa é de cunho documental e bibliográfico, pois além de literatura pertinente acerca da $\mathrm{EaD}$ e da pós-graduação, estudamos os principais documentos que regem o PROFMAT, como o seu Regimento e um Relatório de Avaliação Suplementar. Por fim, destacamos que nossa intenção primeira não é julgar a EaD, nem tampouco o PROFMAT, mas apontar caminhos para compreendermos melhor as possibilidades e limites da tecnologia para o desenvolvimento da pós-graduação stricto sensu no Brasil.

PALAVRAS-CHAVE: Educação a Distância; Novas Tecnologias; Pós-graduação stricto sensu; PROFMAT.

\section{DISTANCE EDUCATION AND DISTANCE POST-GRADUATION STRICTO SENSU IN BRAZIL: A THEORETICAL APPROACH}

ABSTRACT: Distance Education is an educational modality regulated by the Law of Guidelines and Bases in Education, currently predominant in higher education. Current paper discusses what may be done in $\mathrm{DE}$ within the process of the formation of candidates for the master's degree. ED within the context of post-graduation in Brazil is discussed with special reference to the structure and formation of a Master's course in the formation of Math teachers who use DE, or rather, the Professional Master's degree in Mathematics in the national network (PROFMAT). Documentary

Doutor em Educação. Docente EBTT do Instituto Federal do Paraná - Campus Palmas, Brasil.

E-mail: rafael.h.santin@gmail.com

* Graduada em Pedagogia. Especialista em Educação a Distância e Novas Tecnologias pelo Centro Universitário de Maringá (UNICESUMAR). Graduanda em Letras Português/Inglês do Instituto Federal do Paraná (IFPR), Brasil. 
and bibliographical research deal not merely with the literature on DE and postgraduate courses but also with the main documents that foreground PROFMAT, its regime and its Supplementary Evaluation Report. The paper's aim is not to proffer judgment on DE or on the PROFMAT, but to show the way on the improvement of possibilities and limits of technology for the development of a post-graduate course stricto sensu in Brazil.

KEY WORDS: Distance education; New Technologies; Postgraduate course stricto sensu; PROFMAT.

\section{INTRODUÇÃO}

Este artigo tem como tema a aplicação da modalidade à distância em cursos de pós-graduação stricto sensu no Brasil. Nosso objetivo principal é entender o uso que pode ser feito da $\mathrm{EaD}$ no processo de formação de mestres, pressuposto para que se possa pensar os limites e as possibilidades dessa modalidade de ensino em cursos de pós-graduação stricto sensu. Para nossa pesquisa, realizamos um estudo bibliográfico, a fim de conhecer o debate atual sobre a EaD e a pós-graduação no Brasil. Além disso, procuramos apresentar as características de um curso de Mestrado profissional semipresencial, coordenado pela Sociedade Brasileira de Matemática, visando entender o modo como os processos de ensino e de aprendizagem se efetivam nesse contexto.

A importância dessa discussão pode ser verificada nos números que a pósgraduação stricto sensu apresenta no Brasil, bem como na necessidade de se formar profissionais qualificados que estarão à frente do desenvolvimento nacional. No relatório intitulado Mestres 2012: Estudos da demografia da base técnico-científica brasileira, desenvolvido pelo Centro de Gestão e Estudos Estratégicos - entidade vinculada ao Ministério da Ciência, Tecnologia e Inovação -, é possível verificar que a pós-graduação stricto sensu no Brasil apresenta dados bastante tímidos. Em 2010, havia, segundo esse relatório, aproximadamente 610.344 indivíduos com título de Mestre, equivalente a aproximadamente $0,32 \%$ da população brasileira, e 228.879 indivíduos com título de Doutor, equivalente a aproximadamente $0,12 \%$ da população brasileira (CGEE, 2012, p. 16). Em um universo de pouco mais de 200.000.000 
de pessoas, a quantidade de Mestres e Doutores no Brasil é baixa.

Contudo, para afirmar que formamos poucos mestres e doutores é necessário fazer algumas comparações. No mesmo documento supracitado, encontramos um gráfico que apresenta o número de títulos de doutorado concedidos por milhão de habitantes em diferentes países. A Suíça lidera o ranking, formando 486 novos doutores a cada 1 milhão de habitantes; seguida da Suécia, com 359; Finlândia, com 326; Alemanha, com 318; e Reino Unido, com 301. O Brasil aparece na $27^{\mathrm{a}}$ posição, pois forma 58 doutores a cada milhão de habitantes (CGEE, 2012, p. 21).

Nesse contexto, acreditamos que debater sobre o uso da modalidade de ensino a distância em cursos de pós-graduação stricto sensu no Brasil é importante, pois a EaD pode servir para mudar essa realidade e contribuir para o crescimento do país em termos de qualificação acadêmica da população - desde que a excelência seja o imperativo das práticas educativas, e não a lógica mercadológica do custo-benefício.

Diante disso, há, também, o questionamento sobre a relação entre qualificação acadêmica e desenvolvimento nacional. Se observarmos os dados que apresentamos acima, sobre a formação de doutores em diferentes países, vamos perceber que há duas coisas em comum entre os países que ocupam as primeiras posições: 1. são países que formam um número expressivo de doutores; e 2. são países com grandes índices de desenvolvimento humano. Os IDH's de Suíça $(0,917)$, Suécia $(0,898)$, Finlândia $(0,879)$, Alemanha $(0,911)$ e Reino Unido $(0,892)$ são considerados 'muito altos' pela Organização das Nações Unidas. Já o IDH do Brasil $(0,744)$ é considerado 'alto' e o país amarga a 79ª posição - dados de 2013, segundo o site do PNUD (2013). Enfim, percebemos que há uma relação entre o desenvolvimento do país e a qualificação acadêmica. Daí a necessidade de refletirmos sobre o tema proposto neste trabalho.

Considerando que nossa pesquisa é de cunho bibliográfico-exploratório, em primeiro lugar buscamos artigos científicos e livros que tratam da EaD, a fim de refletirmos sobre essa modalidade de ensino e suas potencialidades em relação à pós-graduação stricto sensu. Em segundo lugar, analisamos a estrutura do Mestrado Profissional em Matemática em Rede Nacional (PROFMAT), curso semipresencial coordenado pela Sociedade Brasileira de Matemática. Com esse exemplo, preten- 
demos apresentar limites e possibilidades da EaD na promoção da pós-graduação stricto sensu no Brasil.

\section{DESENVOLVIMENTO}

\subsection{A EAD NO CONTEXTO DA REESTRUTURAÇÃO PRODUTIVA}

Atualmente, estamos vivendo um processo bastante significativo de mudanças em todos os âmbitos da sociedade. Essas transformações originam-se das alterações observadas no setor produtivo. Segundo Nosella (2012), o que está se estruturando em nossa sociedade não é a derrubada do sistema burguês, capitalista, mas sim uma alteração do núcleo do capital, passando do dinheiro, da acumulação da riqueza material propriamente dita, para o conhecimento - daí a ideia, cada vez mais vinculada, que vivemos na 'sociedade do conhecimento'. Estamos passando da etapa 'industrial' para a etapa 'pós-industrial' da sociedade ocidental.

Essa alteração gera mudanças significativas na disposição social. Uma das características da transição da sociedade industrial para a pós-industrial, que consideramos importante para o nosso trabalho, é a ênfase cada vez maior dada à qualidade de vida. Desta forma, novos hábitos passam a ser incorporados ao mercado de trabalho. O que antes era submetido, entre outros aspectos, a tarefas repetitivas, com vistas à otimização do trabalho e dos seus resultados, bem como a um complexo sistema de controle de tarefas, passou a ser tratado pela visão da mobilidade. Ou seja, o controle sobre todo o processo de trabalho tornou-se mais dinâmico e simplificado, proporcionando ao trabalhador maior mobilidade de horários para desempenhar suas funções, aumentando, assim, o bem-estar dos indivíduos trabalhadores. Isto é o reflexo de uma sociedade que não visa apenas quantidade, mas, também, qualidade, criatividade, profissionalismo, capacitação etc. Resumidamente, um profissional polivalente, orgânico, global, adaptável aos interesses do meio e livre para criar.

Diante de tais mudanças, a profissionalização dos indivíduos torna-se cada vez mais necessária. Cabe aqui retomarmos as reflexões de Nosella (2012), segundo o qual o trabalhador é o responsável por sua formação, por sua educação contínua 
e por seu aprendizado, de forma a adquirir novos conhecimentos, hábitos e habilidades para atuar no meio em que está inserido, podendo-o levar à ascensão social e reconhecimento na sociedade pós-industrial.

Se, por um lado, a flexibilidade e mobilidade que caracterizam, hoje, o processo produtivo trouxeram ao trabalhador uma melhor qualidade de vida em relação aos trabalhadores do passado, por outro não trouxe uma efetiva diminuição das preocupações das pessoas com o trabalho. Paradoxalmente, vivemos um período de extremo conforto, mas excessivamente estressante. Nesse contexto, o constante aprimoramento da formação, ou seja, essa educação continuada, torna-se- muitas vezes inviável, principalmente por via do ensino presencial. As atribuições do cotidiano e a carga emocional que os trabalhadores carregam atualmente acabam por deixá-los, muitas vezes, sem muito tempo e motivação para dar continuidade aos estudos.

Assim, com a intenção de expandir e interiorizar a oferta de formação, a modalidade à distância tornou-se uma opção muito eficiente para aqueles que de alguma forma encontraram dificuldade de acesso à formação presencial. Desta forma, a Educação a Distância se coloca como uma modalidade que visa, entre outras coisas, a universalização da educação (tanto no que se refere à graduação, como à pós-graduação lato e stricto sensu, cursos técnicos etc.).

Hoje, graças à interligação dos sistemas informáticos com as telecomunicações, a sociedade dispõe de dispositivos sofisticados de hipermídia que reúnem texto, som, imagem, animação, gráficos, jogos, estações de trabalho interativas em colaboração com todos os países conectados à rede. Desse ambiente, resultante dos avanços tecnológicos impulsionados pelas descobertas da produção eletrônica e da informática, leva a pensar em transformações na escola e, em consequência, na forma de produzir conhecimentos (TELEMBERG, 2004, p. 93).

Telemberg (2004), na passagem acima, destaca um aspecto relevante. A ciência se apresenta de forma singular nas diferentes configurações de tempo e lugar, ou seja, ela se renova, se torna historicamente determinada, assim como a educação. Desta forma, o trecho supracitado nos remete à relação entre ciência, conhecimento e inovação, em que os modelos educativos atualmente passam a ser influenciados e 
transformados pelas inovações tecnológicas, refletindo assim em uma forma diferente de produzir e mediar conhecimentos.

Em resposta a essas inovações, a procura por cursos a distância tornou-se cada vez mais visível. Esse aumento justifica-se, entre outros motivos, por sua estrutura, que é adaptável à rotina dos indivíduos. A flexibilidade faz da EaD uma modalidade de educação mais acessível do ponto de vista de espaço e tempo, oferecendo assim; educação superior para aqueles que teriam dificuldades para estudar por causa da 'roda-viva' da vida. De acordo com Brennand e Brennand (2012, p. 184),

Desde a década de 90, com a Lei de Diretrizes e Bases da Educação Brasileira (LDB), já se fazia referência a uma educação continuada e baseada na comunicação. Por meio do Decreto $n^{0} 5.622$, de 19.12.2005, que regulamenta os Arts. 80 e 81 da Lei 9394/96 (LDB), onde a Educação a Distância é entendida como a modalidade educacional na qual a mediação didático-pedagógica nos processos de ensino e aprendizagem ocorre com a utilização de meios e tecnologias de informação e comunicação, com estudantes e professores desenvolvendo atividades educativas em lugares e tempos diversos. As instituições, os cursos e os programas de educação a distância passam a ser avaliados pelo Sistema Nacional de Avaliação da Educação Superior (SINAES), integrando-se definitivamente às políticas de oferta da formação universitária.

Assim, a EaD vem se consolidando no Brasil como modalidade de ensino, que começa a estabelecer sua identidade e importância no cenário nacional. Os cursos na modalidade $\mathrm{EaD}$ possuem, em sua grande maioria, diretrizes curriculares com base nas determinações do Ministério da Educação, bem como na legislação, garantindo, assim, uma sólida estrutura de funcionamento das instituições. Essa estrutura engloba, entre outras exigências, um material de estudo que possibilite um bom encaminhamento da formação; profissionais capacitados que, independente da distância geográfica, consigam dar suporte ao processo de ensino te aprendizagem; interação constante por parte da equipe docente que, amparada por um modelo pedagógico interativo, dialógico, possibilite aos alunos a construção e ampliação do conhecimento. Esses aspectos são fundamentais em um curso a distância, pois viabilizam condições e subsídios para a formação de um profissional competente, que colabore efetivamente para o desenvolvimento da sociedade em que está inserido. Tudo isso de maneira remota e flexível, tal como as transformações sociais demandam. 


\subsection{A EDUCAÇÃO A DISTÂNCIA NO CENÁRIO BRASILEIRO: ESTRUTURA E FUN- CIONAMENTO}

Somos integrantes de uma sociedade denominada, por alguns autores, como pós-industrial ou 'sociedade do conhecimento'. Tal como observamos no tópico anterior, diante das transformações trazidas por esse novo momento, todas as instituições, em especial as educativas, sofreram significativas mudanças, principalmente após os anos de 1990. Muitas dessas mudanças estão relacionadas ao avanço tecnológico. Essas novas tecnologias que aos poucos passaram a ganhar espaço no cenário brasileiro, principalmente no âmbito educacional, fizeram com que a $\mathrm{EaD}$ passasse a ter importante espaço e relevância na sociedade.

Essa nova modalidade passou a ser regulamentada pela Lei de Diretrizes e Bases da Educação (LDB 9.394/96). A partir de então, a criação e procura por cursos, tanto de graduação como pós-graduação, se intensificaram. Essa regulamentação da modalidade fez com que a EaD ganhasse não apenas um estatuto legal, mas proporcionou, também, a democratização do ensino, principalmente aos que não têm a possibilidade de estudar em espaço e tempo delimitados por encontros presenciais (SOUZA; SILVA, 2011).

Embora a EaD esteja legalmente estabelecida no Brasil, a busca pela qualidade no ensino é um ponto de constantes discussões. Essa qualidade é resultante de dois fatores fundamentais: o suporte tecnológico e o suporte pedagógico. Ambos precisam estar em sintonia e em suas máximas potencialidades, garantindo, assim, a clara interação entre os docentes e os alunos. Ou seja, os recursos tecnológicos aliados aos pedagógicos, quando bem estruturados, criam condições para que o processo de ensino e aprendizagem se efetive (LOPES; FARIA, 2013).

Nesse contexto, verificamos que não há apenas um modelo definido para os cursos de $\mathrm{EaD}$, o que proporciona às instituições certa liberdade para melhor estruturarem-se dentro das exigências estabelecidas em lei. Contudo, todas as instituições devem primar por um objetivo em comum, que, segundo Dias (2011), é levar educação de qualidade ao aluno, garantindo subsídios teóricos e práticos necessários para sustentar o desenvolvimento do processo de formação do indivíduo. Vale ressaltar que, de acordo com a LDB, Lei no 9.394 de 1996, um dos princípios da educação no Brasil é a garantia de um padrão de qualidade (inc. IX, art. $3^{\circ}$ ). 
Por conta de sua natureza e dessa flexibilidade possibilitada pela estrutura legal, a EaD se apresenta como uma modalidade complexa, de modo que se torna relevante pontuar algumas dimensões fundamentais de cunho pedagógico, de recursos humanos e de infraestrutura. Essas dimensões estão descritas no documento intitulado Referenciais de qualidade para educação superior à distância, elaborado pelo Ministério da Educação (MEC) no ano de 2007 (BRASIL, 2007).

Assim, para a estruturação de um curso em EaD, torna-se necessário, primeiramente, a elaboração de um Projeto Político Pedagógico 3 .

O projeto político pedagógico deve apresentar claramente sua opção epistemológica de educação, de currículo, de ensino, de aprendizagem, de perfil do estudante que deseja formar; com definição, partir dessa opção, de como se desenvolverão os processos de produção do material didático, de tutoria, de comunicação e de avaliação, delineando princípios e diretrizes que alicerçarão o desenvolvimento do processo de ensino e aprendizagem (BRASIL, 2007, p. 8).

Como descrito no trecho acima, o Projeto Político Pedagógico (PPP) é o documento norteador do curso. Seus objetivos são organizar e planejar o trabalho pedagógico e administrativo, bem como ter claro o profissional que deseja formar. Sendo assim, além de especificar claramente cada aspecto do curso, é necessário que o PPP aborde as características necessárias para a formação do sujeito social e profissional capacitado.

Além do PPP, o MEC (2007) discrimina a necessidade de um sistema de telecomunicação que permita e promova uma plena interação entre professores, tutores e alunos.

Em primeiro lugar, um curso superior a distância precisa estar ancorado em um sistema de comunicação que permita ao estudante resolver, com rapidez, questões referentes ao material didático e seus conteúdos, bem como aspectos relativos à orientação de aprendizagem como um todo, articulando o estudante com docentes, tutores, colegas, coordenadores de curso e disciplinas e com os responsáveis pelo sistema de gerenciamento acadêmico e administrativo (BRASIL, 2007, p. 11).

O que o MEC está a chamar de projeto político pedagógico (PPP) é mais amplamente conhecido, no ensino superior, como projeto pedagógico de curso (PPC). Vale ressaltar, ainda, que PPP, ou PPC, deve estar articulado com o projeto de desenvolvimento institucional (PDI), que estabelece as diretrizes e práticas no âmbito da instituição que promove o curso. Existe, portanto, uma relação de subordinação entre o PPP e o PDI, de modo que o segundo serve ao primeiro como um eixo norteador. 
Diante disso, podemos constatar que na EaD todo o aparato tecnológico, que envolve telefone, e-mail, videoconferência, fórum de debate, ambientes virtuais de aprendizagem, sistemas de gerenciamento de dados etc., deve estar direcionado à interação dos envolvidos no processo educativo, de modo a promover o processo de ensino e aprendizagem e o funcionamento do mesmo tendo em vista uma perspectiva de totalidade.

A interação entre professor e aluno, principalmente em cursos à distância, é a essência do processo. Estruturalmente falando, no ensino à distância o professor mediador direcionará seus esforços ao ensino de forma a chegar ao seu aluno por meio dos mais diferentes e possíveis recursos - esses recursos são ferramentas síncronas, pelas quais é possível uma mediação imediata, em tempo real entre professor e aluno, como é o caso do telefone, chats, etc.; e ferramentas assíncronas, nas quais a mediação não se efetiva imediatamente, como o e-mail -, buscando sempre anular ou pelo menos encurtar a distância que há entre ele e o aluno (MAIA; MATTAR, 2007).

Segundo o MEC (2007), essa interação necessita ser constantemente fomentada e deve se apoiar em um completo sistema de tutoria com vistas, entre outras coisas, ao atendimento das necessidades apresentadas pelo aluno. Sendo assim, o curso proporcionará vias reais e eficientes de mediação, com o objetivo de efetivar o processo de ensino e aprendizagem.

Nesse processo, é fundamental a ocorrência de três funções primordiais para o estabelecimento de uma educação de qualidade. Por isso, o MEC (2007) salienta a importância da ação conjunta de três profissionais: o professor, o tutor e a equipe administrativa.

Diferente dos cursos presenciais em que o professor é responsável por um grupo relativamente pequeno de alunos, nos cursos de $\mathrm{EaD}$ as aulas podem ter um alcance imenso. Isso significa que o professor deve ser preciso, qualificado e preparado para minimizar as possibilidades de erro, pois um deslize pode ter consequências negativas bastante grandes. Segundo o MEC (2007), esse professor, ao ministrar aula na $\mathrm{EaD}$, precisará selecionar e organizar previamente o conteúdo que será trabalhado, bem como os materiais, definindo bibliografias, vídeos, material extra etc.; ter claro as funções superiores que pretende desenvolver; e acompanhar 
o processo de aprendizagem dos alunos. Podemos observar que, nesse sentido, o professor da EaD é semelhante ao do ensino presencial, mas se diferencia deste na medida em que lida com uma realidade diversa, como número de alunos e recursos disponíveis. Daí a necessidade de se discutir o papel do professor na EaD.

O tutor, tanto o presencial quanto o a distância, também desempenha papel fundamental no processo de ensino e aprendizagem, participando diretamente no encaminhamento pedagógico do curso. Assim, cabe ao tutor à distância, por meio das ferramentas síncronas e assíncronas, dar suporte pedagógico, esclarecer dúvidas, proporcionar ambientes de interatividade e discussão e participar ativamente da avaliação do processo de ensino (professores) e de aprendizagem dos alunos (BRASIL, 2007).

Já o tutor presencial proporciona suporte ao aluno nos polos. Ele auxilia os alunos na realização das atividades, podendo esclarecer dúvidas sobre os conteúdos, sobre o material e sobre a utilização das tecnologias. Além disso, pode atuar ativamente nos momentos presenciais, como de avaliação, aulas práticas nos laboratórios, nos estágios etc. (BRASIL, 2007).

Quanto ao material didático do curso de EaD, o MEC (2007, p. 13) discrimina que deverá ser elaborado "[...] de modo a facilitar a construção do conhecimento e mediar a interlocução entre estudante e professor [...]", ou seja, precisa ser concebido e estruturado visando o desenvolvimento de conhecimentos científicos, a clara comunicação entre aluno e professor por meio de uma linguagem dialógica, bem como o desenvolvimento das funções superiores. Para isso, é necessário que a equipe responsável pela elaboração do material trabalhe articuladamente, buscando e favorecendo a interação e comunicação entre os diversos atores do processo de ensino e aprendizagem.

No que se refere à avaliação, o MEC (2007) especifica a necessidade de avaliações realizadas a distância (pelas plataformas de aprendizagem, conhecidas como ambientes virtuais de aprendizagem) e de avaliações presenciais, sendo que esta última obtém prevalência sobre as demais formas existentes. Essas avaliações devem auxiliar o estudante a desenvolver novas habilidades e estruturar novos conhecimentos. Para isso, é necessário o constante acompanhamento dos alunos na busca de identificar possíveis dificuldades no processo de ensino e aprendizagem, visando saná-las. 
Diante desses apontamentos, temos por base a grandiosidade e complexidade da modalidade a distância e, por isso, a necessidade de uma adequação por parte das instituições às exigências legais do Ministério da Educação, podendo, assim, garantir padrões de qualidade satisfatórios. Contudo, por se tratar de um modelo relativamente novo, a EaD se transforma velozmente a caminho da melhoria, ajustando as imperfeições e incorporando o que de bom foi estruturado.

Dessa forma, vale salientar a necessidade de os cursos à distância tomarem por base as normas de qualidade do MEC, bem como as legislações destinadas a essa modalidade, pois são esses os instrumentos norteadores não apenas para o funcionamento do curso na instituição, mas, também, chaves para um bom trabalho educacional. Quando se trata de cursos de pós-graduação, as exigências também se aplicam.

Em termos legais, os cursos de pós-graduação na modalidade à distância passaram a ser regulamentados pela Resolução $n^{0} 01$ do Conselho Nacional de Educação (CNE) de 03 de abril de 2001 (BRASIL, 2001). Segundo o artigo 3, parágrafos $1^{\mathrm{o}}, 2^{\mathrm{o}}, 3^{\mathrm{O}}$ e $4^{\mathrm{o}}$, os cursos de pós-graduação à distância deverão ser oferecidos por instituições credenciadas pela União, obedecendo as exigências de autorização, reconhecimento e renovação de reconhecimento, conforme estabelecido pelo artigo 80, parágrafos $1^{\circ}, 2^{\circ}, 3^{\circ}$ e $4^{\circ}$ da Lei $n^{\circ} 9.394$, de 20 de dezembro de 1996 (BRASIL, 1996). Além disso, a pós-graduação à distância também é regulamentada pelo Decreto $\mathrm{n}^{0} 5.622$, de 19 de dezembro de 2005 (BRASIL, 2005).

Acreditamos que a preocupação com a regulamentação da EaD é legítima, pois são inúmeros os aspectos positivos que a EaD possibilita aos seus estudantes e, também, à sociedade. Toda a sua estrutura está voltada para a formação de sujeitos, para o desenvolvimento de novas competências que são fundamentais para o funcionamento da sociedade. Por acreditar na complexidade dessa modalidade de ensino (que se tornou tão indispensável), estabelecemos como recorte a pós-graduação stricto sensu à distância.

\subsection{A EAD NA PÓS-GRADUAÇÃO STRICTO SENSU NO BRASIL}

Segundo Almeida (2012), os cursos de pós-graduação já existentes na modalidade à distância no Brasil vêm sendo utilizados como referenciais para a criação de novos cursos. Estes, por sua vez, estão sendo considerados e estruturados pelo viés 
de uma educação participativa, em que os alunos, que na maioria das vezes já são profissionais atuantes do mercado de trabalho, passam a ser impulsionados à liberdade de criação e à reflexão com a intenção de adquirir e aperfeiçoar conhecimentos, podendo gerar resultados significativos não apenas no trabalho, mas também na vida cotidiana como cidadãos.

Essa realidade é mais facilmente observada quando se trata de cursos de pós-graduação lato sensu, de especialização, cuja preocupação é dar uma resposta às novas exigências do mercado de trabalho. A questão que se coloca, para nós, como fundamental é como a EaD vem sendo utilizada na pós-graduação stricto sen$s u$, que tem como foco a formação de pesquisadores e professores para o ensino básico e superior. Partindo desse questionamento, que se torna mais intrigante se tomarmos a atual situação do Brasil em relação à formação de mestres e doutores, analisamos a estrutura de um curso de mestrado profissional semipresencial, destinado aos professores da área da Matemática, o PROFMAT.

Contudo, antes de apresentarmos nossas reflexões sobre o PROFMAT, acreditamos ser importante algumas considerações acerca do conceito de 'mestrado profissional' em EaD.

$\mathrm{O}$ mestrado profissional em EaD passou a ser uma alternativa inteligente para o aperfeiçoamento e continuidade dos estudos no âmbito da pós graduação stricto sensu. Segundo Kramer (2008), a formação continuada - como é o caso do mestrado profissional - é essencial, pois além de ocorrer concomitantemente ao trabalho, possibilita a solução e reformulação de práticas que poderão ser aplicadas de forma imediata, resultando em respostas e soluções para o presente. Nesse sentido, a EaD, utilizada para o desenvolvimento de cursos de mestrado, constitui-se em uma alternativa importante para a formação continuada, que deve ocorrer mesmo diante da realidade de muitos profissionais que trabalham por muitas horas diariamente e têm tempo escasso para investirem em um aprimoramento depois da conclusão da graduação. Assim, Almeida (2012, p. 1062) afirma que:

A Portaria Normativa n. 17, do MEC, de 28 de dezembro de 2009 (Brasil, 2009), preconiza que o mestrado profissional propicia a formação para a prática em atividades técnico-científicas e de inovação por meio do método científico, da pesquisa aplicada e da busca de solução para problemas específicos. Considera-se que formação para a prática significa formação na prática que se desenvolve na relação 
com a teoria, constituindo-se a práxis (SANCHEZ; VAZQUEZ, 2007) e não uma prática centrada no fazer dicotomizado do compreender. Trata-se, portanto, de uma formação complexa, que exige professores bem preparados e experientes, que possam dar conta da tarefa de orientar os demais professores para que possam investigar e teorizar sobre a própria prática, em busca de encontrar solução para os problemas de sua realidade de trabalho e de seu alunado.

Como podemos observar no excerto acima, o mestrado profissional precisa ser pensado de acordo com as suas especificidades, instituídas pelo público atendido e pelo foco na capacitação de profissionais que, muitas vezes, já estão inseridos no mercado de trabalho. Assim, esses cursos parecem estar bastante relacionados com a perspectiva da formação continuada e podem ser uma possibilidade mais concreta para a qualificação pessoal e profissional. Acreditamos que a EaD pode potencializar esse processo.

Além disso, são vários os instrumentos que possibilitam a formação em pósgraduação à distância de indivíduos que, concomitantemente, exercem sua profissão. Desta forma, esses profissionais ao mesmo tempo em que desempenham (integral ou parcialmente) seu ofício, possuem a oportunidade de melhorar sua prática, utilizando assim o seu cotidiano como objeto de estudo e podendo atuar diretamente para o aperfeiçoamento de seu trabalho.

Contudo, para que esses cursos tragam resultados efetivos, Almeida (2012) apresenta alguns princípios que são fundamentais para manter a qualidade da pósgraduação à distância. Segundo a autora, os cursos necessitam ter uma sólida infraestrutura, que abrange, entre outros pontos, a interação e a reflexão em convergência com a construção do conhecimento; a coerência teórica e metodológica dos projetos pedagógicos e o ensino ministrado pela instituição; projetos de formação de educadores visando aproximar, integrar e melhorar as situações formativas que buscam, entre outras coisas, soluções para os problemas imediatos e concretos; formação que integre espaços presenciais e virtuais, visando a flexibilidade de espaço e tempo do processo de ensino e aprendizagem; promoção de uma relação dialógica entre professor e aluno; plena preparação docente, para que o mesmo tenha total competência pedagógica para desempenhar sua função; identificação do perfil dos discentes, para conduzi-los com práticas pedagógicas direcionadas; e estratégias que 
proporcionem aos alunos autonomia para refletir e interagir sobre o processo de ensino e aprendizagem. Tais aspectos visam criar uma relação direta entre aprendizagem e atuação profissional, de modo a traçar caminhos que direcionem o desenvolvimento científico à prática sócio-profissional.

Para melhor compreensão sobre o desenvolvimento de cursos de mestrado profissional à distância, trouxemos o Mestrado Profissional em Matemática em Rede Nacional, o PROFMAT, que segundo a plataforma do programa: "[...] é um curso semipresencial, com oferta nacional, realizado por uma rede de Instituições de Ensino Superior, no contexto da Universidade Aberta do Brasil, e coordenado pela Sociedade Brasileira de Matemática" (PROFMAT, 2014.).

De acordo com a Avaliação suplementar externa do programa (CAPES, 2013), o PROFMAT foi criado e desenvolvido visando melhorar a formação dos profissionais da área de matemática que compõem a Educação Básica. Essa iniciativa foi pensada devido ao baixo desempenho que os alunos estão apresentando nas disciplinas que envolvem as ciências exatas. Com o objetivo de alcançar melhoras no campo da oferta educacional, passou-se a estudar formas de qualificação e valorização dos profissionais da Educação Básica, descritos inclusive no Plano Nacional de Educação (PNE) no ano de 2010, que visa proporcionar formação continuada em nível de pós-graduação lato sensu e stricto sensu para professores da Educação Básica.

Assim, em função da necessidade de formação de professores, a Sociedade Brasileira de Matemática (SBM) elaborou uma proposta de curso de Mestrado Profissional em âmbito nacional. Essa proposta foi aprovada pela CAPES no ano de 2010, originando então o PROFMAT.

Desta forma, o PROFMAT visa atender professores em exercício no ensino básico, especialmente da rede pública e da área de matemática, sem que haja a necessidade de se afastarem de suas funções. Seu propósito é o aprimoramento da formação profissional docente abrangendo todo o território brasileiro, estimulando assim, a melhoria no ensino de matemática por meio de um programa semipresencial. Seu funcionamento encontra-se vinculado ao âmbito da Universidade Aberta do Brasil (UAB) e é coordenado pela SBM (PROFMAT, cap. I, art. 2).

Os mestrandos do PROFMAT são selecionados por meio de um Exame Nacional de Acesso. Os candidatos devem conhecer as normas para o processo seletivo, 
que é realizado nas instituições credenciadas. No ano de 2013, havia 81 instituições credenciadas, espalhadas em todas as regiões brasileiras (PROFMAT, cap. IV, art. 15-17).

O PROFMAT tem duração de 24 meses, de forma que ao final do programa os alunos deverão ter concluído 11 disciplinas, totalizando 88 créditos. No decorrer desses dois anos, o programa se desenvolve em regime semipresencial, estruturado em quatro semestres letivos regulares, "[...] com aulas presenciais nas sextas, sábados e/ou domingos, 3 h por disciplina por semana, durante 12 semanas, em cada um dos semestres regulares" (CAPES, 2013, p. 16) e dois períodos de verão. "Nos períodos de verão, as aulas presenciais são de segunda à sexta-feira, durante 6 horas por dia, pelo período de 4 (quatro) semanas". O trabalho de conclusão de curso é desenvolvido no último período de verão. Em todo o período do PROFMAT “[...] as atividades à distância são apoiadas por material didático elaborado e distribuído gratuitamente pela Comissão Acadêmica Nacional por meio da plataforma moodle, via internet" (CAPES, 2013, p. 16).

Sobre os objetivos do PROFMAT, é proposto:

- Estimular a melhoria do ensino de Matemática em todos os níveis;

- Qualificar professores de Matemática da educação básica em nível de pós-graduação stricto sensu com ênfase no domínio aprofundado de conteúdo, oferecendo um curso de formação profissional que contemple as necessidades advindas do trabalho cotidiano no espaço da escola;

- Incentivar uma postura crítica acerca das aulas de Matemática em níveis fundamental e médio, que enfatize o papel central da competência matemática frente às exigências da sociedade moderna;

- Buscar a valorização profissional do professor por meio do aprimoramento de sua formação (CAPES, 2013, p. 15).

Conforme o trecho supracitado, vemos que formar professores que atendem ao ensino básico e que busquem, entre outras coisas, o aprimoramento profissional, com vistas na melhoria do processo de ensino e aprendizagem em matemática nos diversos níveis de ensino, figura como um dos objetivos principais do programa. Consideramos esse aspecto bastante relevante, pois há uma intenção clara de mudar a realidade educacional por meio da formação docente - algo de que o Brasil precisa com urgência, a julgar pelos últimos resultados das avaliações internacionais do ensino. 
A coordenação do programa fica a cargo do conselho gestor, uma instância deliberativa que presta contas ao Conselho Diretor da SBM. O Conselho Gestor tem, segundo o Regimento do PROFMAT, a seguinte composição:

a) Representante da SBM, designado por seu Conselho Diretor;

b) Representante da CAPES, designado por sua Diretoria;

c) Coordenador Acadêmico Nacional, designado pelo Conselho Diretor da SBM, com mandato de três anos, permitida a recondução;

d) Dois representantes da comunidade científica, designados pelo Conselho Diretor da SBM, com mandato de três anos, permitida a recondução (PROFMAT, cap. II, art. 5).

Como podemos observar no trecho acima, a coordenação do programa em tela é realizada por um órgão colegiado, isto é, sua organização acontece a partir dos princípios da gestão democrática, de acordo com a LDB 9.394/96 (BRASIL, 1996).

Voltando-nos, novamente, aos aspectos pedagógicos, o curso prevê que as atividades à distância poderão ser desenvolvidas ou no polo de apoio presencial, ou mesmo na residência do mestrando, desde que tenha Internet com acesso à plataforma Moodle. Os momentos presenciais das disciplinas, referentes aos períodos regulares, ocorrem no polo de apoio presencial e são previamente estabelecidos de acordo com a disponibilidade dos discentes e precisam totalizar 12 (doze) semanas. Já as disciplinas dos períodos de verão, que normalmente acontecem em janeiro e fevereiro, são desenvolvidas presencialmente no polo de apoio presencial. Cada instituição tem a incumbência de definir da melhor forma o calendário de aulas, devendo respeitar as seguintes orientações: "As aulas acontecem em quatro semanas, durante os meses de janeiro e fevereiro; Para cada disciplina há uma aula por dia de segunda-feira à sexta-feira com duração não inferior a 3 horas" (CAPES, 2013, p. 19).

Quanto ao Trabalho de Conclusão de Curso, o Regimento do programa salienta que o mesmo deverá ser elaborado em forma escrita (produção técnica) e aula expositiva sobre o trabalho elaborado, bem como estar em consonância com os conteúdos da matemática e impactar, de alguma forma, a prática pedagógica na sala de aula. Esse trabalho será avaliado por uma banca formada por pelo menos três avaliadores, de forma que um deles precisa ser externo e os outros dois podem ser da própria instituição a qual o aluno está vinculado. Esses avaliadores compõem a banca de avaliação, que analisará o TCC de acordo com os critérios estipulados pelo PROFMAT. 
Assim, como disposto no Regimento do programa, para que o aluno obtenha o título de mestre, ele precisará ter sido aprovado em pelo menos nove das disciplinas cursadas, ter tido resultado positivo no exame de qualificação, que trata-se de uma única avaliação escrita sobre os conteúdos das disciplinas básicas do curso, bem como ter sido aprovado no TCC e enviar a versão final (com as devidas correções) à Comissão Acadêmica Nacional.

Atualmente, o PROFMAT está se consolidando no cenário da pós-graduação brasileira. Percebe-se, por meio dos documentos analisados, que o programa está crescendo e pode, no futuro, constituir-se como um importante lócus de aprofundamento pessoal e profissional para professores do país inteiro. Além disso, acreditamos que o modelo instituído pelo PROFMAT é sustentável, isto é, pode vir a ser bastante produtivo e de maneira eficiente. Cremos, por fim, que o modelo possa ser reproduzido e até mesmo reinventado, incluindo cada vez mais elementos de $\mathrm{EaD}$ e expandindo o enfoque para as diversas áreas da ciência.

\section{CONSIDERAÇÕES FINAIS}

Diante do que foi discutido, vimos que o cenário brasileiro está sofrendo mudanças que estão levando a uma alta valorização do saber, do conhecimento. Desta forma, muitos profissionais passaram a sentir a necessidade de aprofundar e aumentar seus conhecimentos, o que lhes permitem atuações mais eficazes dentro do âmbito profissional. Diante dessa realidade, o trabalhador passa a buscar uma formação que lhe proporcione uma articulação entre o saber, o conhecimento e a prática profissional.

Um dos espaços para que esse desenvolvimento profissional ocorra é, sem dúvida, a pós-graduação, tanto lato quanto stricto sensu. Com efeito, os cursos de pós-graduação no Brasil têm oferecido oportunidades para o aprimoramento dos indivíduos e para o atendimento da demanda, cada vez maior, de profissionais qualificados. A EaD aparece, aqui, como uma modalidade capaz de levar essa oportunidade a um número cada vez maior de pessoas.

Nesse sentido, trouxemos para o debate o programa PROFMAT, que se apresenta como um mestrado profissional semipresencial e que visa, entre outras coisas, 
possibilitar uma formação ao aluno/profissional capaz de transformar não somente o sujeito particular, mas também o contexto em que vive e trabalha. Na atual conjuntura, o Brasil necessita cada vez mais de professores competentes para ensinar, principalmente nas áreas das ciências exatas. Por isso, entendemos que o PROFMAT figura como um programa capaz de mudar essa realidade e suprir as necessidades educacionais do país. Por meio das possibilidades da EaD, o PROFMAT pode atuar com mais eficácia em um espaço geográfico e político cada vez maior, tornando-se, assim, um modelo a ser replicado.

Isso nos leva a considerar os limites e as possibilidade da EaD para a pósgraduação stricto sensu. Observamos que essa modalidade de ensino pode trazer inúmeras possibilidades, dentre elas a capacidade de atingir um número maior de pessoas e de maneira mais veloz em relação a programas presenciais. Além disso, ela incorpora as TIC's, promovendo modernização em um espaço tradicionalmente resistente a mudanças - embora alunos e professores de cursos presenciais as utilizem com frequência, mas sem explorar grande parte de suas funcionalidades. Contudo, há barreiras para essa inovação e uma delas é a estrutura lógica, que é ruim principalmente no interior do Brasil. Outra limitação é o conservadorismo na relação orientador-orientando: a impressão que temos é que a preferência ainda é pela orientação presencial, ao passo que a orientação remota parece ser uma espécie de tabu para ambos, orientadores e orientandos.

\section{REFERÊNCIAS}

ALMEIDA, M. E. B. de. Formação de educadores a distância na pós-graduação: potencialidade para o desenvolvimento da investigação e produção de conhecimento. Educ. Soc., Campinas, v. 33, n. 121, p. 1053-1072, out./dez. 2012. Disponível em: < http://www.scielo.br/pdf/es/v33n121/a08v33n121.pdf>. Acesso em: 10 jul. 2014.

BRASIL. Lei $\mathrm{n}^{\circ}$ 9.394, de 20 de dezembro de 1996. Estabelece as diretrizes e bases da educação nacional. Disponível em: < http://www.planalto.gov.br/ccivil_03/leis/ 19394.htm >. Acesso em: 12 jul. 2014. 
BRASIL. Decreto $\mathrm{n}^{\mathbf{0}} \mathbf{5 . 6 2 2}$, de 19 de dezembro de 2005. Regulamenta o art. 80 da Lei $\mathrm{n}^{\circ}$ 9.394, de 20 de dezembro de 1996, que estabelece as diretrizes e bases da educação nacional. Disponível em: < http://www.planalto.gov.br/ccivil_03/_ Ato2004-2006/2005/Decreto/D5622.htm>. Acesso em: 12 jul. 2014.

BRASIL. Resolução CNE/CES no 1 , de 3 de abril de 2001. Estabelece normas para o funcionamento de cursos de pós-graduação. Disponível em: < http://portal.mec. gov.br/seed/arquivos/pdf/tvescola/leis/CES0101.pdf> . Acesso em: 14 jul. 2014.

BRASIL. Ministério da Educação e Cultura. Referenciais de qualidade para educação superior à distância. Brasília: MEC, 2007. Disponível em: < http://portal.mec. gov.br/seed/arquivos/pdf/legislacao/refead1.pdf> . Acesso em: 20 jul. 2014.

BRENNAND, E. G. de G.; BRENNAND, E. de G. Inovações tecnológicas e a expansão do ensino superior no Brasil. Revista Lusófona de Educação, v. 21, p. 179198, 2012. Disponível em: < http://www.scielo.gpeari.mctes.pt/pdf/rle/n21/n21a10. pdf $>$. Acesso em: 15 jul. 2014.

CAPES. Avaliação Suplementar Externa do Programa de Mestrado Profissional em Matemática em Rede Nacional (PROFMAT). Brasília: CAPES, 2013. Disponível em: <http://www.profmat-sbm.org.br/files/Arquivos\%20do\%20Site/Relatorio/PROFMAT_Av_Suplementar.pdf $>$. Acesso em: 02 jul. 2014.

CENTRO DE GESTÃO E ESTUDOS ESTRATÉGICOS (CGEE). Mestres 2012: estudos da demografia da base técnico-científica brasileira. Brasília: Centro de Gestão e Estudos Estratégicos, 2012.

DIAS, D. F. Gestão, estrutura e funcionamento de cursos em EaD. Maringá: Cesumar, 2011.

KRAMER, S. Alfabetização, leitura e escrita: formação de professores em curso. São Paulo: Ática, 2008.

LOPES, L. F.; FARIA, A. A. O que e o quem da EaD: história e fundamentos. Curitiba: InterSaberes, 2013. (Série Fundamentos da Educação). 
MAIA, C.; MATTAR, J. ABC da EaD. São Paulo: Pearson Prentice Hall, 2007.

NOSELLA, M. L. Gestão do conhecimento e de pessoas. Maringá: Cesumar, 2012.

PROFMAT. Regimento do Mestrado Profissional em Matemática em Rede Nacional. Rio de Janeiro: PROFMAT, 2012. Disponível em: < http://www2.profmat-sbm. org.br/docs/PROFMAT-Regimento_2012.pdf>. Acesso em: 02 jul. 2014.

PROGRAMA DAS NAÇÕES UNIDAS PARA O DESENVOLVIMENTO. Ranking IDH Global 2013. Brasília, 2013. Disponível em: < http://www.pnud.org.br/atlas/ranking/Ranking-IDH-Global-2012.aspx> . Acesso em: 01 ago. 2014.

SOUZA, M. M. P. de; SILVA, W. V. K. de M. Fundamentos históricos da educação a distância: políticas e práticas do EaD no Brasil. Maringá: Cesumar, 2011.

TELEMBERG, T. Tecnologia na educação: as representações docentes em séries iniciais. 2004. Dissertação (Mestrado em Engenharia de produção) - Universidade Federal de Santa Catarina, Florianópolis, 2004.

Recebido em: 15/09/2017 Aceito em: 16/04/2018 